\title{
The Use of Space Swimmer Bars as Shear Reinforcement in Reinforced Concrete Beams
}

\author{
Moayyad Al-Nasra \\ Civil and Infrastructure Engineering Department, \\ American University of Ras Al Khaimah, AURAK, Ras Al Khaimah, UAE \\ moayyad.alnasra@aurak.ac.ae
}

\begin{abstract}
The sudden nature of shear failure in reinforced concrete beams is undesirable and requires special attention. This undesirable mode of failure pushes the design engineers to use higher factor of safety against the shear forces. Several alternatives to the traditional stirrups were introduced in the past including the concept of the swimmer bars. This study focuses on special kind of swimmer bars. The new swimmer bars system used in this study is called space swimmer bars system which requires no welding to be assembled. The space swimmer bars concept is new and effective in improving the shear performance of reinforced concrete beams. The results of this study will be compared with the traditional stirrups, as well as the welded swimmer bars. The space swimmer bar is basically a reinforcing bar bent several times in the three dimensions forming special configuration along with its coupling swimmer bar. This configuration makes the shear reinforcement system act as plane-crack interceptor rather than linear bar-crack interceptor. This new system is not only effective in taking care of the shear forces, but also it is economical compared to the traditional stirrups and the welded swimmer bars. There is no available data to show the performance of the welded swimmer in the long run, but this new type of swimmer bars system requires no welds. In addition, welding shear reinforcement bars does not seem to be desirable in the construction engineering practice. Several beams will be tested. One group of beams are reinforced with standard traditional stirrups as shear reinforcement and they are used as control samples. The second group of beams used welded swimmer bars as shear reinforcement system. The third group of beams used the new space swimmer bars as alternative to the existing shear reinforcement systems in reinforced concrete beams. The results of the three groups of beams will be presented. Flexural cracks as well as shear cracks will be monitored with the increase in the applied load. The deflection at the mid-span of the beam will also be monitored as the applied load is gradually increased.
\end{abstract}

Keyword- Space swimmer bar, Deflection, Shear, Crack, Stirrup

\section{INTRODUCTION}

The main objective of the design of reinforced concrete beams is safety. The sudden failure mode requires higher factor of safety. The design engineer has to make sure that the mode of failure is acceptable and gives enough warning before failure. The shear failure is not one of the desirable mode of failures and should be avoided. Reinforced concrete beams are one of the common structural elements that carry transversal loads mainly by flexure and shear. The common design approach is to design the beam for flexure then design the beam for shear. The available design codes emphasizes on the ductile flexural failure by reducing the amount of steel reinforcement in the tension area, in order to make sure that the longitudinal tension bars yield first. While the design for shear focuses on providing enough shear resistance exceeding the applied shear force by a margin of safety factor. The shear resistance comes from two different sources; the concrete and the shear reinforcing bars. The concrete shear strength depends on the cross section of the beam, and the concrete compressive strength. Large applied shear force requires shear reinforcing bars of large diameter placed at closer spacing.

The design codes provide factor of safety enough to make sure that the beam will survive applied loads during its expected service life. Punching shear in slabs is considered one of the governing factor in the design of flat slabs and raft foundations [1]. Several researcher provided some solution for shear reinforcement including swimmer bars [2]. These swimmer bars added significant shear resistance [3]. Creative pyramid swimmer bars were used [4]. The results were compared with the traditional slab reinforcement.

Beams subjected to large shear force exhibit diagonal cracks initiated near the supports. These diagonal cracks have the tendency to widen and propagate moving toward the center of the beam. These cracks are proven to propagate at a faster rate compared with the bending flexural cracks. Steel stirrups, which are shear reinforcing bars, are placed perpendicular to the longitudinal flexural bars and used to reduce the shear cracks. Several alternatives to the traditional stirrups were explored including U-links swimmer bars and spliced swimmer bars $[5,6]$. 
Experimental research showed that the effective depth of reinforced concrete beams is not a sensitive parameter to the shear strength of the beam [7]. The shear strength was the target of experimental investigations as related to several parameters including the effective depth. Other experimental research utilized the use of bent-up bars to improve the shear performance of reinforced concrete beams [8]. The experimental results showed that the bent-up bars have the potential to improve the shear performance of reinforced concrete beams [9]. The use of bent-up bars is a matter of choice. The bent-up bars used to be common practice in the past, but its popularity decreased lately for practical reasons.

Swimmer bars were used effectively to improve the shear strength of the reinforced concrete beams [10, 11]. Several attempts to replace the welds in the swimmer bars due to the uncertainty in the performance of the welds $\mathrm{n}$ the $\log$ run were explored [12.13]. Investigating the use of several types of swimmers bars were explored and proven to be comparable to the performance of the welded swimmer bars $[14,15]$. The main focus of these studies was to improve the shear resistance and to reduce cost.

In this study three groups of beams were prepared. The first group is regular beams reinforced with ordinary standard stirrups. The second group used welded swimmer bars as shear reinforcement. The third group used new type of space swimmer bars. The beams in the third group are reinforced with the new space swimmer bars. The results of this group are compared with the beams reinforced with stirrups and the beams reinforced with the welded swimmer bars. This study covers also the swimmer bar spacing in order to study the effect of increasing the shear reinforcement provided by the swimmer bars on the beam performance in shear. Three different values of swimmer bar spacing were used to study the shear performance of the reinforced concrete beams. Large longitudinal flexural reinforcing bars were added at the bottom of simply supported beams to make sure that the beams will not fail by flexure in order to shift the focus toward the shear strength of these beams. The space swimmer bars can be easily constructed and assembled without the need for welding or special fabrication. The space swimmer bars can be spliced with the longitudinal flexural bars in order to add rigidity to the swimmer bars system. The speed of building the steel cage is also one of the major advantages of the space swimmer bars.

According to the ACI Code provision for shear design, the design of beams for shear is to be based on the following relation [16]:

$V u \leq \Phi V n$

Where, $V_{u}$ is the total factored shear force applied at any given section in the beam.

$V n=V c+V s$

Where, $\mathrm{Vn}$ is the nominal provided shear strength, $\mathrm{V}_{\mathrm{c}}$ is the concrete shear strength. $\mathrm{V}_{\mathrm{s}}$ can be calculated as follows

$V s=\frac{\Phi A v f y s d}{S}$

and for inclined bars

VS

$=\frac{\Phi A v \text { fys } d(\sin \beta+\cos \beta)}{S}$

Where, $A_{v}$ is the area of one stirrup, $\beta$ is the angle of the shear reinforcing bars with the horizontal, $S$ is the shear reinforcing bar spacing, and $\mathrm{f}_{\mathrm{ys}}$ is the yield strength.

The nominal concrete shear strength can be expressed in it simplified form as follows

$V c=0.167 \lambda(b w d) \sqrt{f c^{\prime}}$

Where: $b_{w}$ and $d$ are the section dimensions, and $\lambda=1.0$ for normal weight concrete

\section{SWIMMER BARS}

A swimmer bar is, in its traditional form, an inclined steel bar where both ends are bent to be in line with the longitudinal flexural bars. These bars are usually welded together in order to add stiffness to the steel shear reinforcing system. This added rigidity helps the swimmer bars to act as plane-cracks interceptor. Fig. 1 shows typical standard swimmer bars. Many different configurations can be derived from this standard shape, including adding intermediate swimmer bars and adding cross-bracings. Fig. 2 shows the new space swimmer bars used in this research. Fig. 3 shows two space swimmer bars assembled together as couple. The space swimmer bars should be accurately bent with appropriate angles in order to splice these bars effectively with the longitudinal flexural steel bars. Each two space swimmer bars are assembled together forming a complete loop. These two swimmer bars are wired together initially as shown in Fig. 3. 
ISSN (Print) : :2319-8613

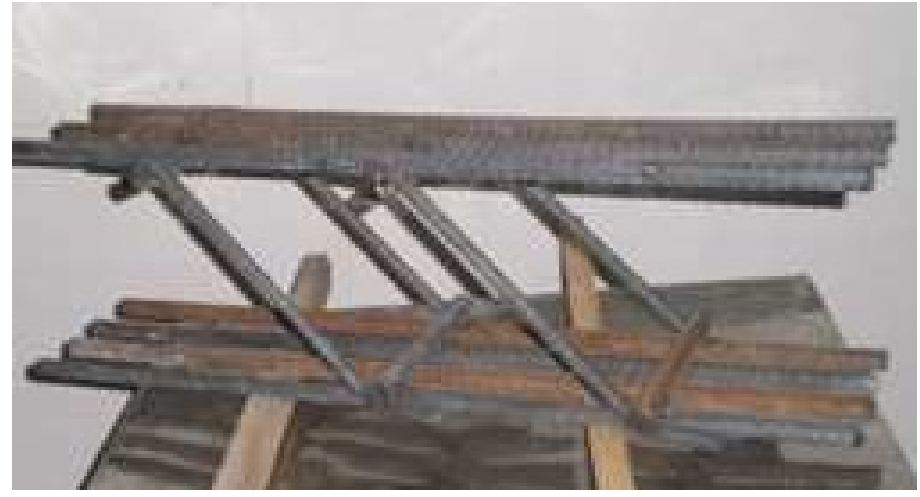

Fig. 1. Typical welded swimmer bars

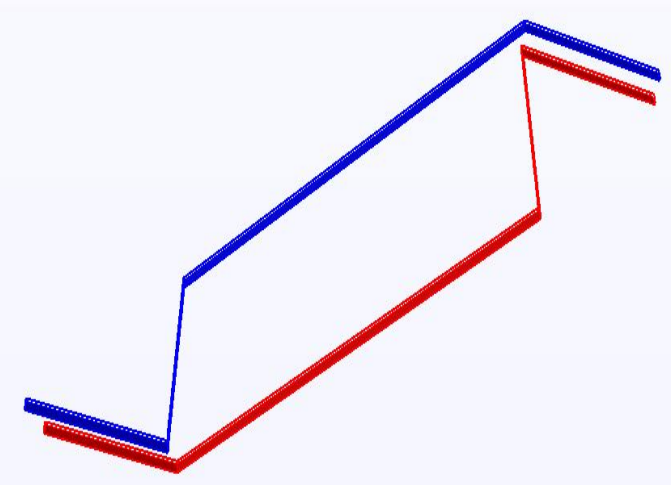

Fig. 2. Coupled space swimmer bars

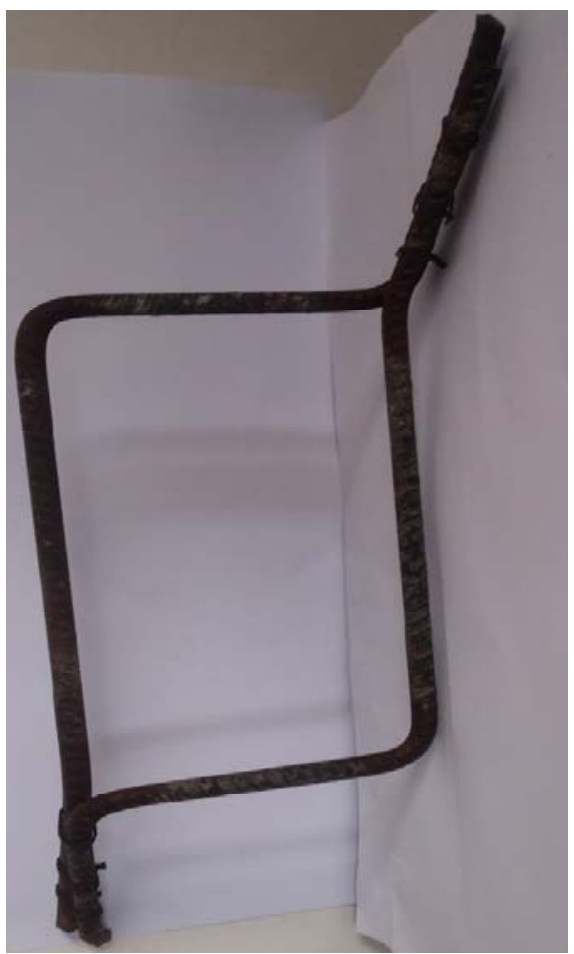

Fig. 3. Assembled space swimmer bars loop. 


\section{III.TESTED BEAMS}

The experimental test of beams for the shear strength is mainly to study the effect of the use of the special type of swimmer bars called here space swimmer bars. The results of the shear strength test of beams made with the space swimmer bars are compared with the results of beams made with welded swimmer bars, and the results of the beams made with regular stirrups. The swimmer bars spacing is also a factor in this experimental research. The test focuses on the effect of the swimmer bar spacing on the shear strength of the beam subjected to two point loads. Deflection at the mid-span of the beam is also taken into consideration given all other variables. The cracks, especially the diagonal shear cracks, will be monitored as the applied load increases.

The longitudinal tension flexural steel reinforcement is designed such that the beam fails by shear, since the focus of this study is on the shear performance of reinforced concrete beams. The mode of failure is, by design, shear failure at the beam supports. The increase in the beam strength is the reflection of the increase in the shear strength of that beam. Top longitudinal steel reinforcement is used here, making the beams doubly reinforced beams with compression steel at the top part of the beams. Many parameter were fixed in this study including the beam dimensions, and the concrete compressive strength. The shear span over the effective depth is calculated to be 2.5 for all of the tested beams. The concrete compressive strength is measured according to ASTM C 192-57. Concrete cubes were prepared and tested on the $28^{\text {th }}$ day to measure the concrete compressive strength of the concrete used in this study. The average compressive strengths of three cubes is considered here at the $28^{\text {th }}$ day of the concrete age. The average concrete compressive strength is calculated to be $29.87 \mathrm{MPa}$. The variation between the average concrete compressive strength and the three tested cubes does not exceed 0.5 $\mathrm{MPa}$.

The total length of the beam mold is $2000 \mathrm{~mm}$. The cross-sectional area is $200 \mathrm{~mm}$ width by $250 \mathrm{~mm}$ depth. All beams are made of the same typical dimensions. The effective length of the beam is taken to be $1800 \mathrm{~mm}$, giving $100 \mathrm{~mm}$ space at either supports. All beams were reinforced with $4 \Phi 16 \mathrm{~mm}$ as bottom steel, and $3 \Phi 14$ as top steel. The control beam used here is the beam with standard stirrups. This beam is also reinforced for shear with $10 \Phi 8 \mathrm{~mm}$ standard stirrups spaced at $60 \mathrm{~mm}$ in the two shear sides of the beam. The swimmer bars used as alternative to the standard stirrups are of $\Phi 10 \mathrm{~mm}$. These swimmer bars are either welded or bent. Fig. 4 shows typical steel reinforcement detail used in this study. The figure shows the location of the swimmer bars at the left side and at the right side of the beam for a distance of $550 \mathrm{~mm}$. The angle of the sloped swimmer bar " $\beta$ " is kept constant at a value of 37 degrees measured with respect to the horizontal longitudinal bars.

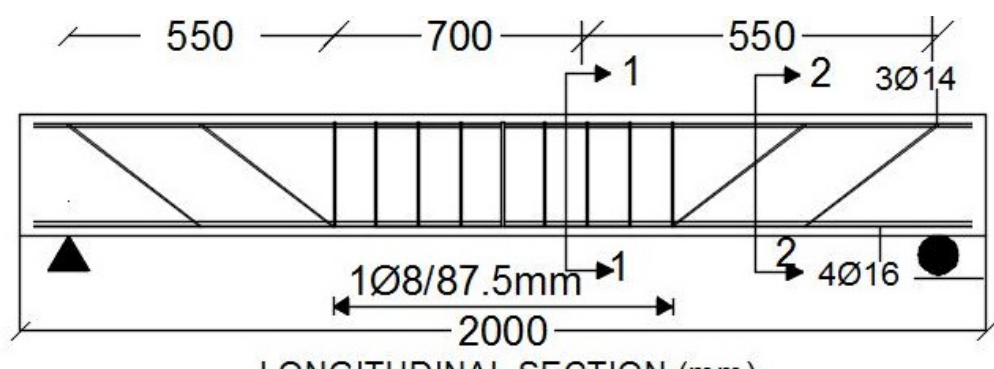

LONGITUDINAL SECTION (mm)

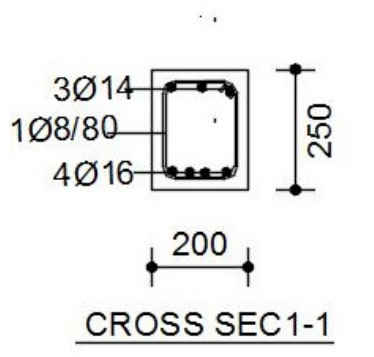

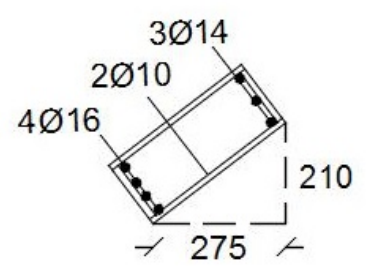

CROSS SEC2-2

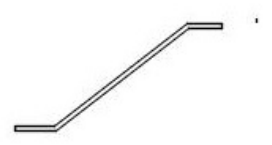

TWO SWIMMER BARS

Fig. 4. Typical steel reinforcement used in this study

\section{IV.TEST PROCEDURE}

A total of seven main beams were prepared to be tested in this study. The first is reinforced with standard stirrups for shear and is designated as the control beam. The second group of beams were reinforced with welded swimmer bars. The welded swimmer bars were placed at three different values of bar spacing. The third group is reinforced with space swimmer bars using the same values of bar spacing as the welded swimmer bars system. The beams were painted with white paint in order to make it easier to detect and follow the progress of the cracks. Marks were placed at significant points at the beams to show the location of the applied loads and the location of the supports. 
Sufficient flexural steel is used for all beams to make sure that the beam failure is controlled by shear failure. The beams were loaded with two concentrated point loads of the same value located at $550 \mathrm{~mm}$ for either support. Fig. 5 shows the typical test setup used in this study. The figure shows the location of the applied loads. Fig. 6 shows the experimental set up used in this study. The load is applied by a loading jack against rigid base member. This applied load is gradually increased until the beam failure by shear is reached. The deflection at the mid-span of the beam and the cracks were monitored throughout the testing procedure.

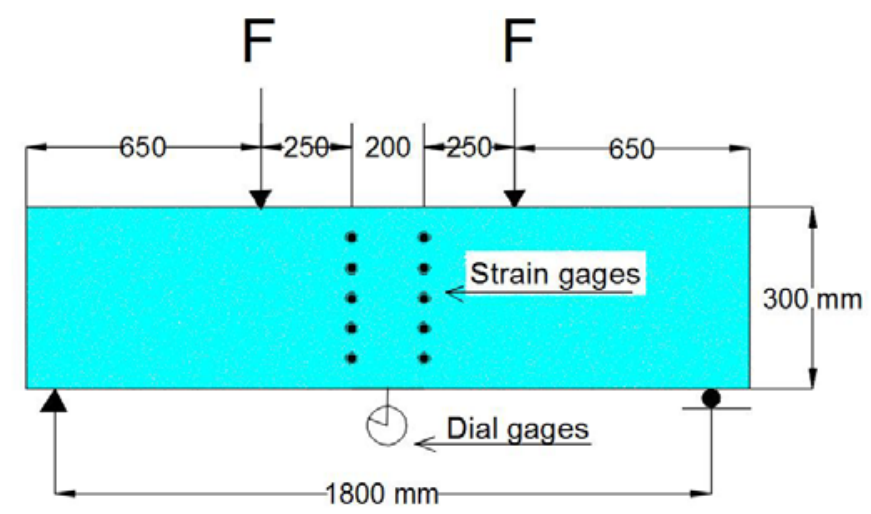

Fig. 5. Test set up drawing

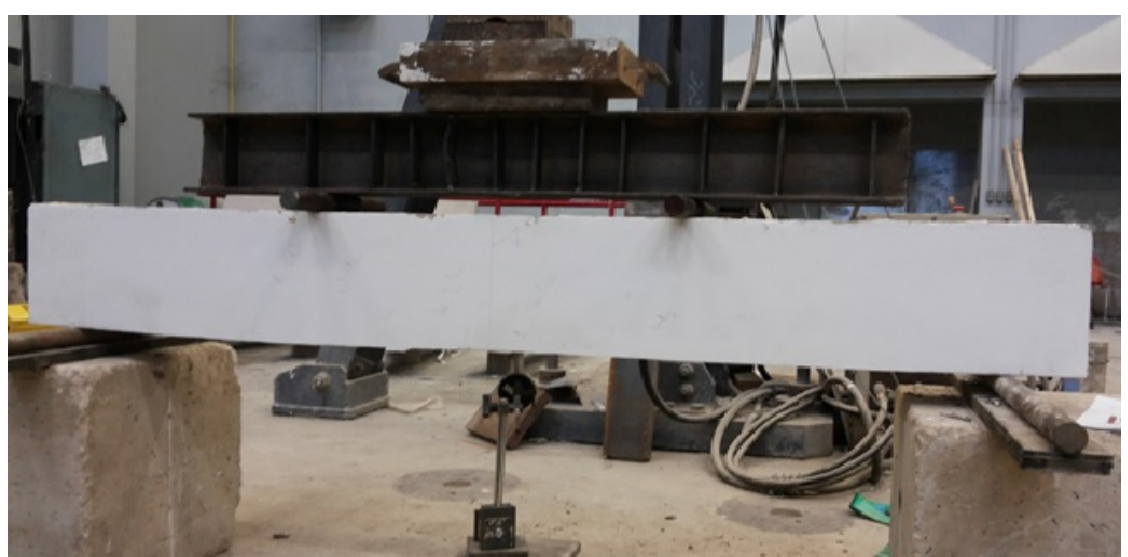

Fig. 6. Typical experimental set-up

\section{TEST RESULTS}

The applied load is increased gradually at a paste just enough to take readings, and observe the progress of the concrete cracks. The cracks became visible initially at a load of $60 \mathrm{kN}$. The initial crack starts at the support with smaller angle. Soon after, other cracks become visible and start moving toward the center of the beam at larger angles. The flexural crack starts at approximately 90 degrees near the mid-span. Fig. 7 shows the typical shear failure of a beam reinforced with space swimmer bars. The initial and major shear crack start at angle of approximately 30 degrees measured with respect to the horizontal line. The following shear cracks start at higher angle. Soon after the major shear crack becomes visible bending cracks start to appear at the mid-span of the beam. The width of the shear cracks is visibly larger than the width of the flexural cracks. The shear cracks propagate at a faster rate than the flexural cracks. 


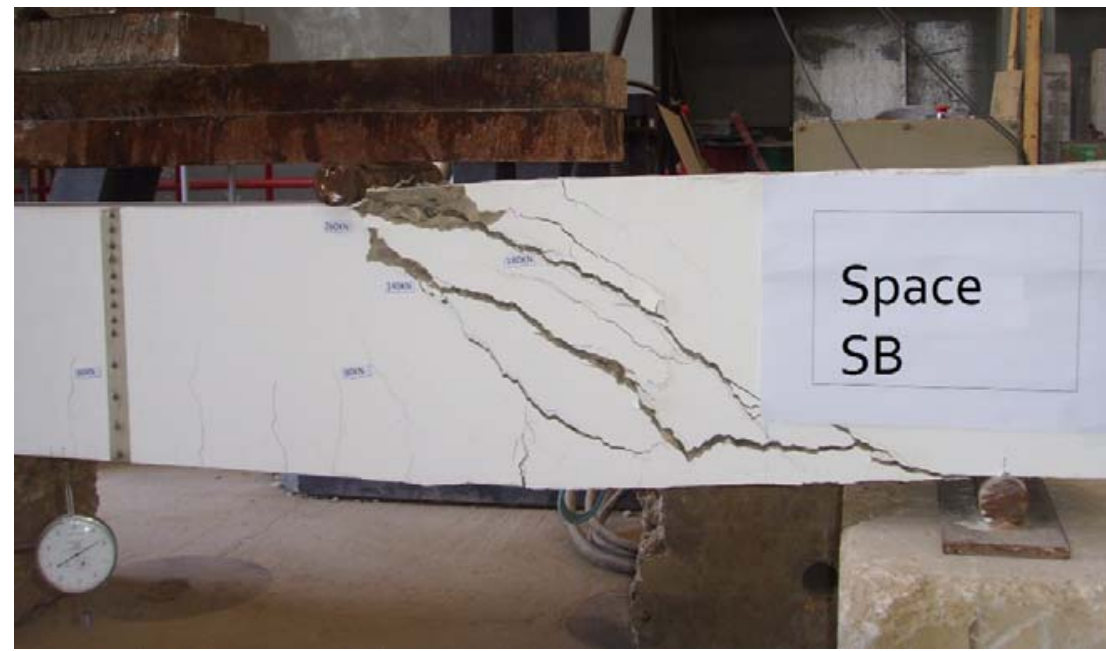

Fig. 7. Typical shear failure.

Fig. 8 shows the shear strength of beam reinforced with swimmer bars. The welded swimmer bars exhibit a slight increase in shear strength especially at high range of bar spacing. When the spacing of the swimmer bars gets smaller the difference in shear strength between the welded swimmer bars and the space swimmer bars becomes negligible. Fig. 9 shows the shear strength of three types of beams of equivalent shear reinforcement steel by weight. The figure shows that the use of the swimmer bars as shear reinforcement system is more efficient than the regular stirrups. The welded swimmer bars system showed an improvement in the beam shear performance of $49 \%$ over the beams reinforced with standard stirrups. The space swimmer bars system also showed a comparable improvement of $46 \%$ over the beams reinforced with standard stirrups.

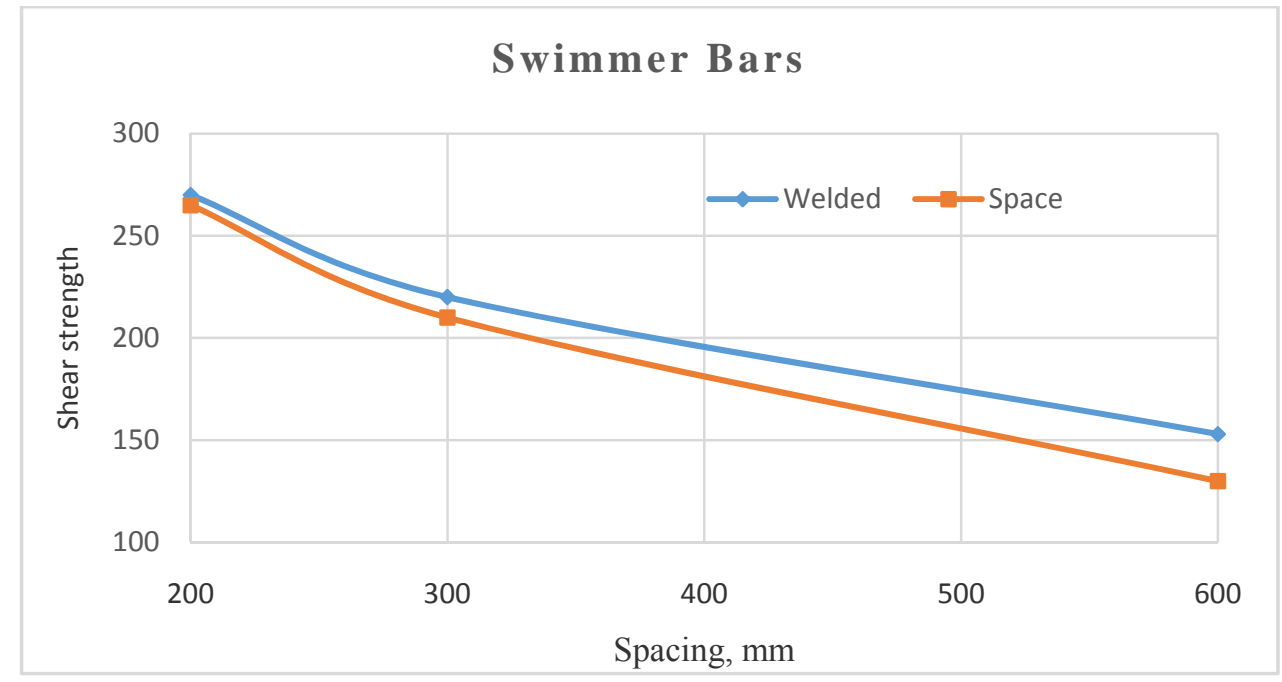

Fig. 8. Shear strength of beams reinforced with swimmer bars 


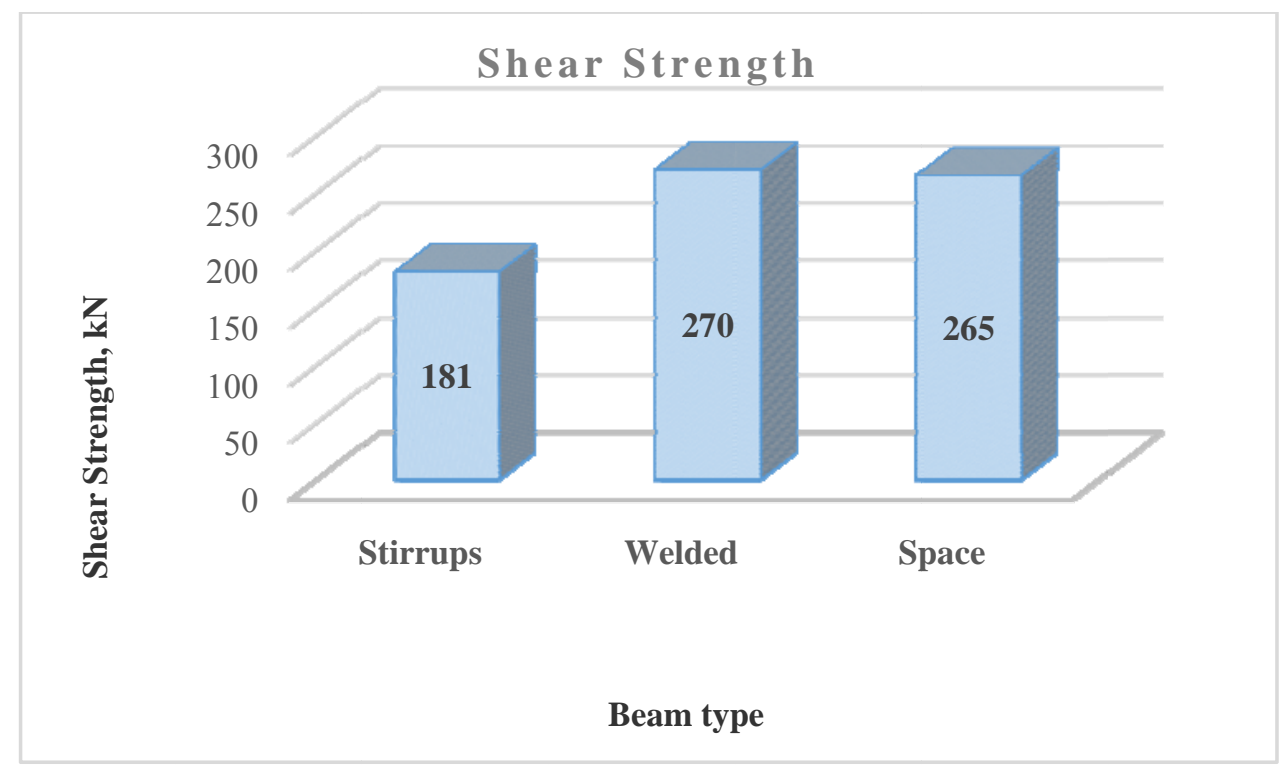

Fig. 9. Shear strength of beams of similar shear reinforcement by weight.

Fig. 10 shows the beam deflection of the three different types of beams at failure. This shows that the rigidity of the beams reinforced with swimmer bars for shear is higher than the rigidity of the beams reinforced with the standard stirrups. Also it can be seen from this figure the rigidity of the beams reinforced with welded swimmer bars for shear is very similar to the rigidity of the beams reinforced with the new space swimmer bars system.

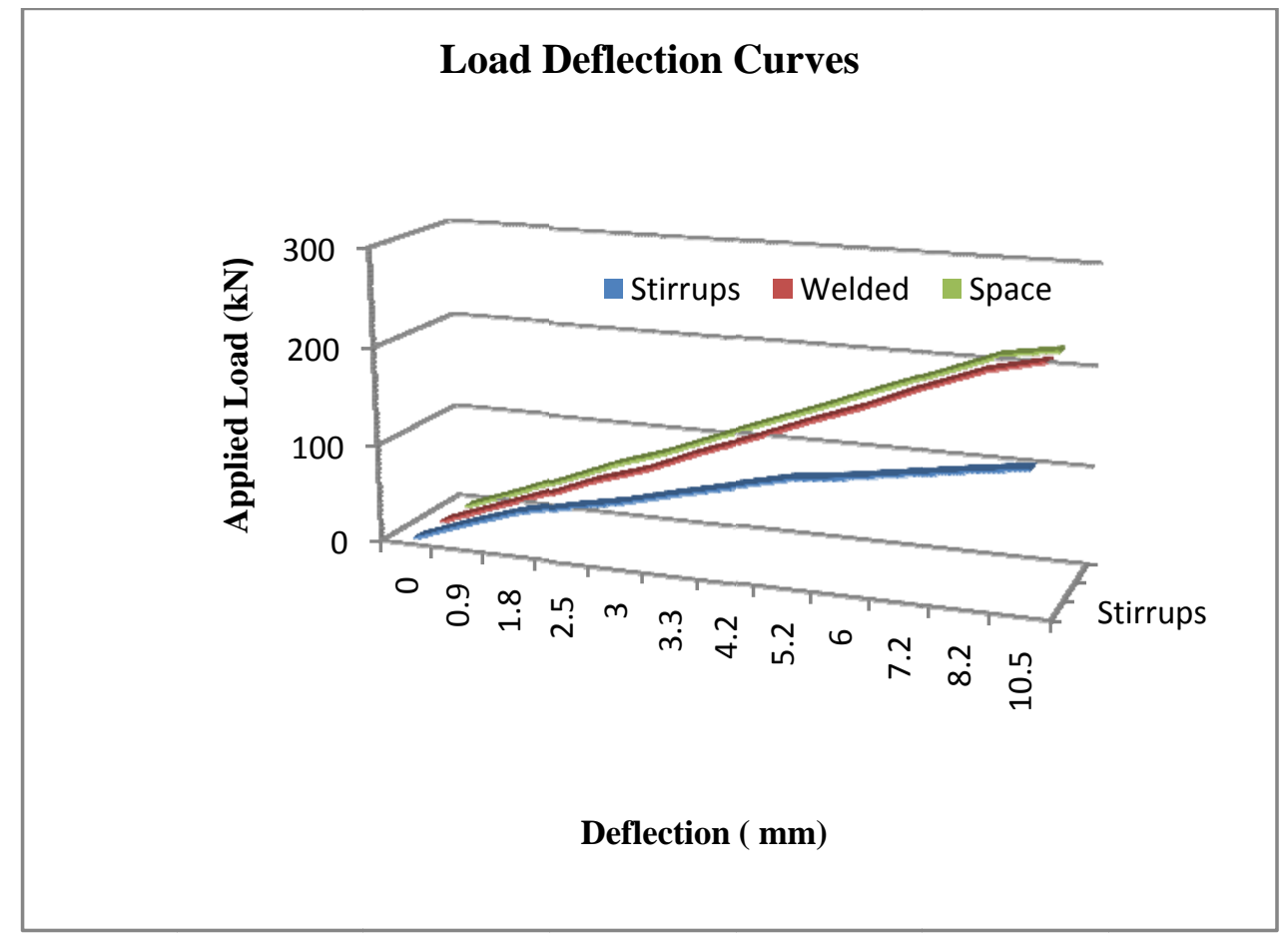

Fig. 10. Load deflection relation of the three types of beams before failure

Fig. 11 shows the relationship between the shear strength of beams reinforced with space swimmer bars for shear and the reciprocal of the swimmer bars spacing. The relationship is linear that can be expressed as follows $V s=\frac{37500}{S}+80$

The coefficient of determination of this equation denoted as $\mathrm{R}^{2}$ is 0.995 which reflects the accuracy of the correlation. The other parameters affecting the value of the shear strength are fixed in this case, including the area of steel bars, beam depth, steel strength, and the angle $\beta$. The numerical value 37500 includes all of these parameters. 


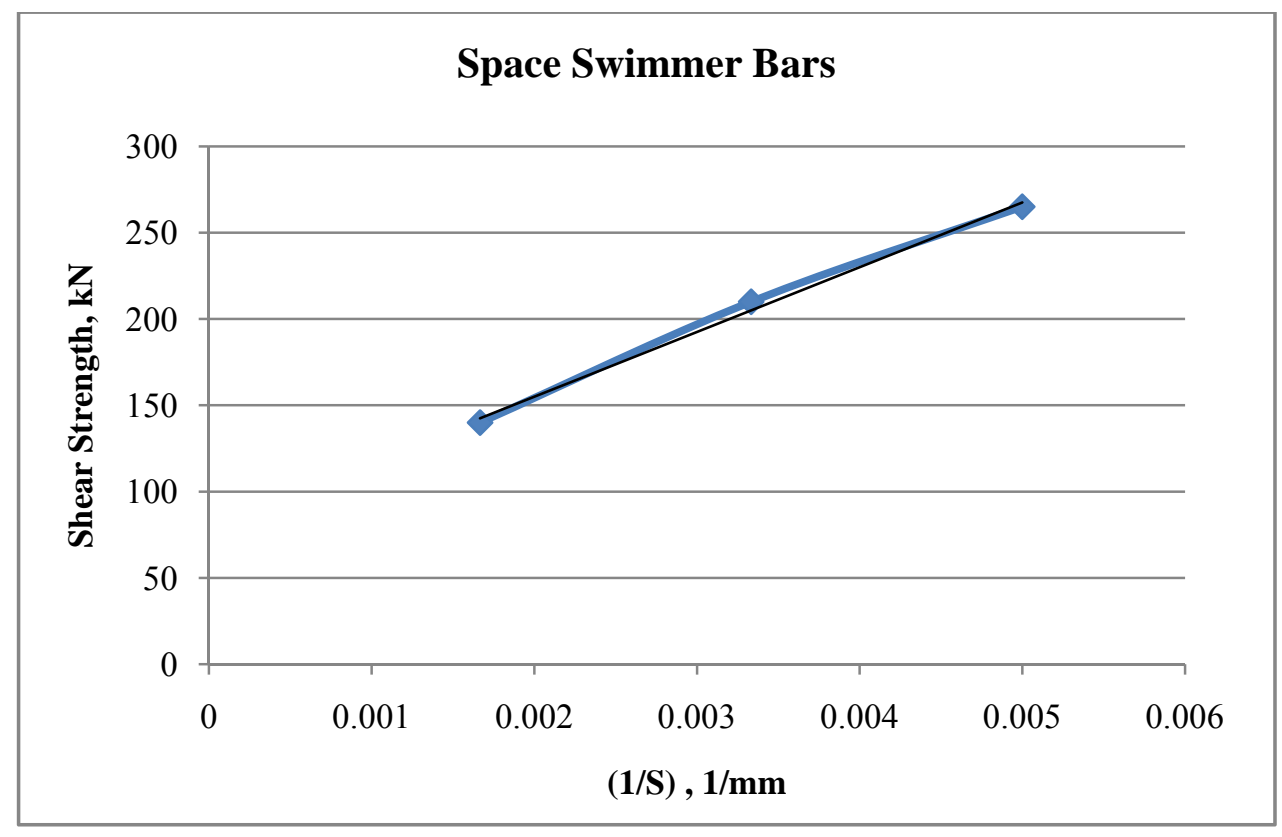

Fig. 11. Shear strength-bar spacing relationship of space swimmer bars system.

\section{VI.CONCLUSION}

This study showed that the use of the new space swimmer bars system to be economical and effective to be used as shear reinforcement in reinforced concrete beams. The beams reinforced with the new space swimmer bars system for shear performed as good as the beams reinforced with the welded swimmer bars system in terms of shear strength and rigidity. The use of swimmer bars as shear reinforcement, in general, improves the beam shear performance by approximately 50\% compared to the performance of the beams reinforced with the traditional stirrups. The space swimmer bars system has many advantages over the welded swimmer bars system including simplicity, cost, and construction time. It is also considered safer in the long run due to the uncertainty of the welds performance

\section{REFERENCES}

[1] M. Al-Nasra, and L. Wang "Parametric Study of Slab-On-Grade Problems: Due to Initial Warping and Point Loads," ACI Structural Journal, Vol. 91 No. 2, pages 198-210, March 1994.

[2] I. Duweib, M. Al-Nasra, A. Najmi, "Investigating the Use of Swimmer Bars as Punching Shear Reinforcement of Reinforced Concrete Flat Plates", International Journal of Engineering Research and Industrial Applications, Vol. 6, No. 1, ISSN 0974-1518, pages 127139, February 2013.

[3] M. Al-Nasra, A. Najmi, I. Duweib, "Effective Use of Space Swimmer Bars in Reinforced Concrete Flat Slabs", International Journal of Engineering Sciences and Research Technology, Vol. 2 No. 2, ISSN: 2277-9655, pages 195-201, February 2013.

[4] M. Al-Nasra, I. Duweib, A. Najmi, "The Use of Pyramid Swimmer Bars as Punching Shear Reinforcement in Reinforced Concrete Flat Slabs", Journal of Civil Engineering Research, Vol. 3, No. 2, DOI: 10.5923/J.JCE.20130302.02, pages 75-80, March, 2013

[5] M. Al-Nasra, N. Asha, "The Use of Bolted U-Link Swimmer Bars in the Reinforced Concrete Beams," International Organization of Scientific Research, Journal of Engineering (IOSRJEN), Vol. 3 , Issue 10 , Version 5, ISSN Print: 2278-8719, ISSN Online: 22503021, DOI: 10.9790/3021-031052632, ANED: 0.4/3021-031052632, pages 26-32, October, 2013.

[6] M. Al-Nasra, N. Asha, "Investigating the Use of Spliced Swimmer Bars as Shear Reinforcement in Reinforced Concrete Beams", ," International Organization of Scientific Research, Journal of Engineering (IOSRJEN), Vol. 05 , Issue 02, Version 02, ISSN Print: 2278-8719, ISSN Online: 2250-3021, DOI:- 05224754, ANED: 0.4/3021-05224754, ESCI-MML 3021-0502-4754, pages 47-54, Feb. 2015

[7] L. Sneed and A. Julio, Effect of Depth on the Shear Strength of Concrete Beams without Shear Reinforcement, USA Portland and cement Association, 2008

[8] N. Hamid, The Use of Horizontal and Inclined Bars as Shear Reinforcement, Master Thesis, University of Technology, Malaysia, 2005

[9] A. Najmi, M. Al-Nasra, N. Asha, "Improved Shear Performance of Bent-up Bars in Reinforced Concrete Beams," International Journal of Engineering Sciences and Research Technology, Vol. 2, Issue 5, ISSN: 2277-9655, pages 1264-1268, May 2013

[10] M. Al-Nasra, N. Asha, A. Najmi, T. Abulebdeh, "The use of swimmer bars as shear reinforcement in reinforced concrete beam" American Journal of Engineering and Applied Science, Vol. 6, Issue 1, ISSN Print: 1941-7020, ISSN Online: 1941-7039, DOI: 10.3844/ajeassp.2013.87.94, pages 87-94, March 15, 2013.

[11] M. Al-Nasra, "Shear Failure Investigation of Reinforces Concrete Beams with Swimmer Bars", Journal of Civil and Construction Technology, Vol. 4, No. 2, DOI: 10.5897/JCECT2013.0251, ISSN 2141-2634-2013, pages 56-74, February 2013

[12] M. Al-Nasra, N. Asha, A. Najmi, "Investigating the Use of Swimmer Bars as Shear Reinforcement in Reinforced Concrete Beams," International Refereed Journal of Engineering and Sciences (IRJES), Vol. 2, Issue 4, pages 40-49, ISSN (online): 2319-183X, ISSN (print): 2319-1821, April 2013

[13] M. Al-Nasra, N. Asha, "Shear Reinforcements in the Reinforced Concrete Beams," American Journal of Engineering Research (AJER), Vol. 2, Issue 10, ISSN online: 2320-0847, ISSN print: 2320-0936, ANED: 30.0847/0210191199, pages 191-199, October 2013. 
[14] M. Al-Nasra, "Investigating alternatives in Shear reinforcements in the Reinforced Concrete Beams," International Journal of Civil and Structural Engineering- IJCSE, SEEK, Volume 2, Issue 2, ISSN: 2372-3971, pages 168 - 172, October 2015.

[15] N. Asha, M. Al-Nasra, Abdelqader Najmi, "Optimizing the Use of Swimmer Bars as Shear Reinforcement in the Reinforced Concrete Beams", International Journal of Civil and Structural Engineering, Vol. 3, No. 2, November 2012, pages 313-320, ISSN 0976-4399, DOI: $10.6088 /$ ijcser.201203013030, 2012

[16] ACI 318-14. Building Code Requirements for Structural Concrete Commentary, USA, 2014.

\section{AUTHOR PROFILE}

Prof. Moayyad Al-Nasra is a professor of civil engineering at the American University of Ras Al Khaimah. He has more than 30 years' experience in teaching and research mostly in the US. His research interest includes finite element modeling, Construction materials, and Solid and fracture mechanics. 